\title{
Atuação ética e contextualizada nos estágios básicos supervisionados em Psicologia da Saúde: um relato de experiência de docentes
}

\author{
Ethical and contextualized performance \\ in supervised basic internships in Health \\ Psychology: an experience report by professor
}

\author{
Aline Tonheiro Palmeira' ${ }^{1}$ \\ Maria Ivana Amado Chaves Guerra² (1)
}

${ }^{1}$ Autora para correspondência. Escola Bahiana de Medicina e Saúde Pública (Salvador). Bahia, Brasil. alinepalmeira@bahiana.edu.br ²Escola Bahiana de Medicina e Saúde Pública (Salvador). Bahia, Brasil. mariaivanaguerra@bahiana.edu.br

\begin{abstract}
RESUMO | A Psicologia, enquanto ciência e profissão, passou por algumas propostas curriculares e, com isso, discussões sobre ensino em psicologia têm se adensado, assim como os debates acerca das práticas na formação, com o reconhecimento da contribuição de estágios básicos ao longo do curso. O Sistema Único de Saúde auxiliou sobremaneira na demonstração do quanto a aproximação das diversas realidades em saúde ainda se faz necessária para uma atuação engajada da categoria. O objetivo deste trabalho é discutir a importância dos estágios para a formação da futura psicóloga. Utilizamos o relato de experiência de professoras do Internato em psicologia, uma modalidade específica em estágio básico, para problematizar a relevância do desenvolvimento de competências profissionais, que auxiliem na qualificação dessa atuação. Esse Internato está presente no quarto ano do curso de Psicologia de uma faculdade em Salvador, Bahia, e propõe a passagem de pequenos grupos de estudantes por campos variados da saúde e das organizações de trabalho. Compreendemos que o transitar do estudante por diversos contextos de prática na saúde e ter a mediação de uma professora são diferenciais para a formação na área. Essa proposta de estágio contribui para o desenvolvimento de um profissional crítico, ético, reflexivo e mais atento aos fenômenos que ocorrem com aqueles a quem presta serviço e a si mesmo. Estudos como este e outros com metodologias diversas podem auxiliar na construção de práticas profissionais e pedagógicas em Psicologia mais reflexivas e comprometidas com a nossa realidade brasileira.
\end{abstract}

PALAVRAS-CHAVE: Psicologia. Estágio. Saúde. Ética. Internato em Psicologia.
ABSTRACT | Psychology, as a science and profession, has gone by some curricular proposals and, as a result, discussions about teaching in psychology have become more intense, as well as debates about practices in training with the recognition of the contribution of basic internships throughout the course. The Unified Brazilian Health System (SUS) helped a lot in demonstrating how much the approximation of the different realities in health is still necessary for an engaged performance of the category. The objective of this work is to discuss the importance of internships for the future psychologist's formation. We used the teachers of the internship in psychology's experience, a specific modality in basic internship, to problematize the relevance of the development of professional skills which help in the qualification of this performance. This internship is present in the fourth year of the Psychology course at a college in Salvador, Bahia, and proposes the passage of small groups of students through different fields of health and work organizations. We understood that the transit of the student through different contexts of practice in health and having the mediation of a teacher are differentials for training in the area. This internship proposal contributes to the development of a professional more critical, ethical, reflective and attentive to the phenomena that occur with those to himself and those whom he provides service. Studies like this and others with different methodologies can help in the construction of professional and pedagogical practices in Psychology that are more reflective and committed to our Brazilian reality.

KEYWORDS: Psychology. Internship. Health. Ethics. Internship in Psychology. 


\section{Introdução}

A Psicologia no Brasil começou a ser lecionada, enquanto disciplina autônoma, na segunda metade do século XIX, com influência dos modelos europeus e estadunidenses, evento que precede o ensino da Psicologia na era universitária (Lisboa \& Barbosa, 2009; Antunes et al, 2006; Collares-da-Rocha \& Lima, 2019). A década de 1950 , por sua vez, foi marcada pela busca da regulamentação da profissão e da atuação do profissional de Psicologia, com a articulação da Associação Brasileira de Psicotécnica (ABP) e do Instituto de Seleção e Orientação Profissional da Fundação Getúlio Vargas (ISOP/FGV) com o Conselho Nacional de Educação (Esch \& Jacó-Vilela, 2012; Collares-da-Rocha \& Lima, 2019). Por conta dos muitos impasses entre o Ministério da Educação e a Associação Brasileira de Psicólogos, apenas em 1962, a profissão e o curso de Psicologia foram oficialmente regulamentados no Brasil (Lisboa \& Barbosa, 2009) e organizados em três níveis de formação: bacharelado, licenciatura e formação do psicólogo (Lei n. 4.119, 1962). A partir desse momento, Instituições de Ensino Superior (IES), sejam elas universidades, centros universitários ou faculdades (públicos ou privados) começaram a expandir a oferta desse curso no país.

No entanto, com golpe de 1964 e a ocorrência da ditadura militar no Brasil, os espaços de trocas entre psicólogas foram impactados. A repressão característica desse período, entre outros efeitos, impediu que a profissão, recém-regulamentada, produzisse reflexões sobre si mesma, além da própria dificuldade da categoria se organizar de maneira crítica frente ao sistema instaurado (Jacó-Vilela \& Degani-Carneiro, 2012; Antunes, 2012). Uma das críticas mais presentes nesse período era o quanto conhecimentos e práticas reproduziam a construção que vinha de outros países, mesmo com marcadas diferenças econômicas e sociais entre as realidades desses locais e a brasileira (Jacó-Vilela \& Degani-Carneiro, 2012). Apenas a partir de meados da década de 1970 e 1980, mais de dez anos após a regulamentação da profissão, que as psicólogas passaram a lançar luz sobre o seu fazer. Nesse sentido, Jacó-Vilela e Degani-Carneiro (2012) e Correia e Dantas (2017) destacam a importância da Psicologia Social e a influência de psicanalistas argentinos na construção de novas formas de fazer Psicologia no Brasil, na construção de um trabalho articulado às demandas de um grupo ou comunidade, em que a teoria está auxiliando a prática, não determinando-a.
Além disso, a crise econômica da década de 1980 contribuiu para a inserção da profissional em outros locais de atuação, para além do contexto clínico tradicional hegemônico da psicoterapia no consultório particular (Dimenstein, 1998; Jacó-Vilela \& Degani-Carneiro, 2012, Ferreira Neto, 2008; Mello \& Teo, 2019). Dada a hegemonia do modelo psicoterápico, as profissionais psicólogas encontraram e construíram barreiras na sua atuação no setor saúde e no trabalho em equipe, transpondo, muitas vezes, o modelo clínico individual para hospitais gerais e psiquiátricos, ambulatórios de saúde mental e de clínica geral e postos de saúde na atenção básica, não garantindo uma mudança sóciopolítica nessas práticas (Ferreira Neto, 2008; Mello \& Teo, 2019). O modelo clínico hegemônico da psicoterapia, ainda baseado em tradições europeias e estadunidenses, permaneceu sem atender às necessidades apresentadas pela população de determinados locais de atenção à saúde. Este modelo desconsiderava, muitas vezes, fatores como classe social, raça e gênero, elementos importantes e característicos da organização da população brasileira, marcada fortemente pela desigualdade social, racismo e diferenças de gênero, e com demandas que pediam ações que extrapolassem o modelo exclusivamente baseado no atendimento individual.

Ao passo em que psicólogas atuantes na saúde compreendiam que não dispunham dos recursos teórico-práticos necessários para o trabalho que se apresentava em seus contextos, professoras de Psicologia, inseridas nos mais diversos contextos acadêmicos, também identificaram a necessidade de transformações no currículo formativo, tentando diminuir a distância entre as práticas emergentes e as discussões acadêmicas.

Não se pode falar em percepções e mudanças lineares e homogêneas, mas os movimentos sociais da década de 1980, que foram responsáveis pela redemocratização do país, Reforma Sanitária Brasileira e Reforma Psiquiátrica, influenciaram enormemente nas concepções de direito, de cidadania e, consequentemente, de saúde, provocando reflexões nas mais diversas áreas do saber-fazer da Psicologia no Brasil. Especificamente no que se refere à Reforma Psiquiátrica, este movimento solicitou das psicólogas um posicionamento crítico e visão ética sobre a situação que era vivida no contexto geral dos manicômios e também na sua relação com a sociedade como um todo (Lüchmann \& Rodrigues, 2007; Macedo \& Dimenstein, 2016), estabelecendo interlocução com 
os direitos humanos. Nesse sentido, Rosato (2011) discute o quão transformadora essa articulação pode ser para o saber-fazer da psicóloga, uma vez que a profissional não se ocupa de sujeitos isolados, mas da situação humana, da dignidade e do sofrimento das pessoas nos contextos em que vivem.

Os diversos avanços na área passaram a exigir, cada vez mais, uma profissional que conseguisse avaliar, compreender e intervir nos diversos contextos de sua atuação, considerando sujeitos individuais, grupos e coletividades, seja na esfera pública ou privada. Assim, desde a formação em Psicologia, essa discussão sobre o trabalho da psicóloga nas mais diversas áreas de atuação tem se tornado necessária e já possui impactos na organização da graduação na área em todo o país. As propostas curriculares têm ofertado e valorizado estágios supervisionados (básicos e específicos), que precisam proporcionar uma imersão ética, crítica e embasada nos contextos de práticas. essa imersão deve estar localizada em um tempo e espaço, respeitando as populações, grupos e indivíduos ali envolvidos, contextualizadas com as necessidades históricas e emergentes. Os estágios básicos têm oportunizado a compreensão desse trabalho da psicóloga tal como precisa ser desenvolvido socialmente, uma vez que possibilitam a inserção do aluno de maneira gradual e ao longo do curso, viabilizando discussões acerca do vivido nesses locais. A proposta desses estágios é justamente auxiliar na compreensão das múltiplas possibilidades de ação da psicóloga, sempre considerando que suas práticas são construídas também a partir das demandas dos locais em que a psicóloga se insere.

A produção nacional sobre o tema tem crescido, seja apresentando pesquisas empíricas e relatos de experiência sobre a importância dos estágios, seja com trabalhos de revisão bibliográfica (Collares-da-Rocha \& Lima, 2019; Macedo, \& Dimenstein, 2016). O papel do professor e supervisor, o reconhecimento da dinamicidade das experiências mediante os contextos de práticas e a necessidade de se reconhecer o quanto o currículo precisa estar bem articulado à realidade brasileira são alguns elementos que vêm sendo debatidos nos últimos anos (Pitombeira, Xavier, Barroso \& Oliveira, 2016; Silva Neto \& Oliveira, 2015; Mendes, Fonseca, Brasil \& Dalbello-Araújo, 2012; Silva, Pinheiro \& Laurendon, 2020), mas discussões acerca do papel do estágio na formação da futura psicóloga, experiências bem sucedidas nas inovações das propostas de estágio, a influência dos estágios básicos para o estudante de psicologia ainda são aspectos que podem ser melhor estudados e debatidos.

O objetivo deste artigo é, portanto, discutir a importância dos estágios supervisionados para a formação da psicóloga brasileira. Utilizaremos o relato de experiência de uma modalidade de estágio básico, como uma forma de discutir o desenvolvimento de competências que versem sobre uma atuação contextualizada, crítica e proponente de mudanças na área da saúde.

\section{As Diretrizes Curriculares Nacionais (DCN) em Psicologia e a importância dos estágios supervi- sionados em saúde}

Nas décadas de 1980 e 1990, assim como o setor saúde, a organização da educação sofreu diversas mudanças no Brasil, no nível das responsabilidades federais, estaduais e municipais. Nesse sentido, novas composições e reflexões foram trazidas para os currículos de todos os profissionais de saúde. Temos, a partir de 1996, o surgimento da Lei de Diretrizes e Bases da Educação (LDB) n. 9394 (1996), cujo propósito, em linhas gerais, era estabelecer um diálogo entre União, Estados, Distrito Federal e Municípios, para a organização de competências e diretrizes para o ensino (em todos os níveis, incluindo os cursos de graduação), com o pacto de um currículo mínimo (Yamamoto, 2000). A implementação da LDB e as consequências advindas da sua execução têm sido muito debatidas, incluindo-se críticas à sua forma, mas se reconhecendo também avanços que ocorreram, aspectos que não poderão ser aprofundados neste artigo, mas que podem ser explorados em produções mais específicas sobre o assunto (Yamamoto, 2000, Fernandes, 2001).

A partir da divulgação da LDB, foram construídas as Diretrizes Curriculares Nacionais (DCN) (Resolução n. 5, 2011), que se constituíram como um acontecimento histórico importante, por terem sido fruto de debates e negociações entre diversos atores sociais e entidades representativas. Essas entidades representativas embasaram o entendimento dos perfis de egressos para a formação dos estudantes de Psicologia de forma a estruturar as competências e as habilidades para alcançar esse perfil. Tais aspectos são apresentados como um domínio de conhecimentos psicológicos básicos (Bernardes, 2012).

Ao longo do tempo, algumas propostas foram desenvolvidas e aprofundadas, contemplando discussões 
sobre a divisão do curso de Psicologia em formação de psicólogo e bacharelado e a organização do curso em núcleo comum (formação generalista) e ênfases curriculares (momento de concentração e aprofundamento em alguma área de atuação profissional). A discussão sobre os estágios também está presente nas DCN de 2011 (Resolução n5, 2011), que destacam que: "os estágios supervisionados visam assegurar o contato do formando com situações, contextos e instituições, permitindo que conhecimentos, habilidades e atitudes se concretizem em ações profissionais, sendo recomendável que as atividades do estágio supervisionado se distribuam ao longo do curso" (Resolução n. 5, 2011, p.20).

No contexto brasileiro, atualmente, alguns cursos de Psicologia já inserem os estudantes em situações práticas desde o primeiro semestre, construindo gradualmente as intervenções possíveis para esse discente, iniciando, por exemplo, com a prática e o treinamento em observação, na perspectiva dos estágios básicos. Os estágios profissionalizantes ou específicos, por sua vez, permanecem ocorrendo ao final do curso e devem refletir o amadurecimento do fazer da Psicologia por esse aluno, que está concluindo a graduação.

Ao final da década de 1990, críticas a esse currículo ainda eram tecidas mencionando o quanto a discussão sobre o Sistema Único de Saúde (SUS) era incipiente e o quanto os alunos desconheciam as realidades em que atuariam, como na saúde mental (Romano, 1999; Macedo \& Dimenstein, 2016). Reconhece-se a importância de, ainda na formação universitária em Psicologia, aproximar os alunos dos contextos de saúde e que essas discussões e práticas, na graduação, instrumentalizam esses estudantes a atuarem em contextos diversos com embasamento teórico, competências que envolvam habilidades e atitudes éticas, responsáveis, críticas e propositivas, elementos fundamentais para qualquer campo de atuação, mesmo nos mais recentes.

Nesse sentido, a formação em Psicologia deve funcionar efetivamente para ampliar a aptidão dos estudantes no uso dos conhecimentos psicológicos básicos para a pesquisa, análise, prevenção, promoção da qualidade de vida e atuação em processos psicológicos e psicossociais. O currículo consiste em um processo de produção de cultura e relações de poder, e isso ressalta a importância da comunidade científica na construção das reformas curriculares.
Por isso, é fundamental apresentar os diversos posicionamentos dos atores sociais e entidades envolvidas para a elaboração de propostas curriculares democráticas que contemplem as aspirações e ideais da maioria (Bernardes, 2012).

Dessa forma, o SUS e, em seguida, o Sistema Único de Assistência Social (SUAS), se configuram como dois sistemas brasileiros que apontam para uma forma de se pensar cuidado e direitos no Brasil e a prática nessas instâncias solicita do profissional psicólogo que novas formas de atuação sejam organizadas, para além do modelo da clínica tradicional hegemônica. $O$ reconhecimento dos elementos contextuais, a exemplo de altos índices de violência de gênero, grande consumo de álcool, regionalidades, bem como a identificação do funcionamento da dinâmica de famílias, o atendimento à grande demanda de uma Unidade Básica de Saúde (UBS), a complexidade do trabalho em equipe são aspectos a serem integrados na prática psicológica (Ferreira Neto, 2008; Macedo \& Dimenstein, 2011).

Por sua vez, os antigos modelos curriculares, carregados em conteúdos programáticos e que pouco faziam interlocução com a prática, foram e estão sendo revistos, com a proposta de incluírem referenciais práticos, contemplando variadas áreas de atuação na saúde (Centro de Atenção Psicossocial (CAPS), consultório de rua, outros dispositivos de cuidado menos institucionalizados), novos conhecimentos (como os advindos da Psicologia Social, Comunitária e de interseções com outras áreas, como a ideia de clínica ampliada) e com autores brasileiros (como Cecília Minayo, Magda Dimenstein, Jessé Souza, Paulo Amarante, Joel Birman, Djamila Ribeiro).

A partir de experiências de estágios em Psicologia da Saúde, psicólogas e estudantes têm oportunidades de exercitar habilidades para identificar as necessidades sociais e de saúde da população atendida, ao se colocarem ativas na escuta e na intervenção sobre os processos psicológicos e psicossociais, para favorecer a resolutividade das ações em saúde. As atividades de estágio explicitadas por Dimenstein e Macedo (2012) e Hüning, Costa, Silva e Silva (2013) adequaram-se à proposição das diretrizes do SUS, ao estabelecerem associação entre os âmbitos de atuação e a Política Pública de Saúde no Brasil.

Assim, estar presente em diversos espaços de atuação, através dos estágios básicos em Psicologia, 
permite fazer visitas diversificadas a muitas instituições de saúde, voltando o olhar para questões diferentes das enfocadas na psicoterapia e que são extremamente relevantes, como qualidade de vida; prevenção, proteção e promoção da saúde; valorização do trabalho em equipe; importância do trabalho intersetorial, os diversos impactos dos determinantes sociais na saúde das pessoas, entre outros.

A práxis dialogada ao longo da formação, que inclui diversos elementos teóricos e práticos, proporciona a compreensão de que a relação dialógica é base para o aprendizado e para a mudança, ganhando valor de destaque em relação aos conteúdos desvinculados de uma reflexão sobre possíveis impactos dessa forma de pensar (Soares \& Veríssimo, 2010). Relações éticas são, dessa forma, trabalhadas na graduação, convidando o estudante a refletir que elas não envolvem apenas a ética profissional, mas também, uma forma de se estabelecer relações e entender as situações vividas (Soares \& Verissimo, 2010).

As discussões mais recentes em torno da formação em Psicologia têm abarcado esses aspectos. A partir de 2018, ano indicado pelo Conselho Federal de Psicologia como o ano da formação em Psicologia, foram iniciadas discussões para a elaboração das novas DCN para o curso. A Associação Brasileira de Ensino da Psicologia (ABEP) promoveu uma série de reuniões entre psicólogas e entidades de classe, encontros que resultaram na Resolução n. 597 (2018). Assim, a contribuição social sobre fenômenos e processos humanos emergiu como um dos aspectos transversais da formação teórico-prática da Psicologia e se destacou a necessidade do caráter científico, presencial, generalista, crítico, humanista, ético, reflexivo e complexo da formação na área (Resolução n. 597, 2018). Os estágios, através das DCN, configuram-se como uma forma importante de se construir uma perspectiva mais articulada entre saberes e práticas e como uma via de inserção do estudante em possíveis cenários de atuação, tornando mais complexo seu olhar sobre as realidades brasileiras, assim como, promovendo uma formação mais crítica e contextualizada.

\section{Metodologia}

Este artigo consiste em um relato de experiência de duas professoras acerca de um estágio básico que desenvolviam, pertencente à formação de um curso de graduação em psicologia, no formato de Internato. Trata-se de uma perspectiva qualitativa, que utilizou a observação e a descrição de atividades realizadas nessa modalidade de estágio, ao longo do período de 2016 a 2020. Assim, essas atividades dizem respeito: às aulas com conteúdo mais teórico, às aulas realizadas em campo de estágio, junto aos grupos de alunos, bem como às reuniões com outras professoras e com as coordenações, das quais participaram, ao longo do período estabelecido.

Por se tratar de um relato de experiência das próprias autoras, esse trabalho não foi submetido à avaliação de um comitê de ética em pesquisa, mas obedece aos inúmeros procedimentos éticos, como o sigilo de pessoas envolvidas no compartilhamento das atividades, a atenção a não produzir riscos ou prejuízos com o relato das reflexões e o reconhecimento que relatar a experiência de um estágio inovador, que é o de formato em Internato, pode gerar contribuições para a prática do ensino em Psicologia de maneira ampliada.

Diante disso, os resultados envolvem três grandes temas: a importância dos estágios supervisionados básicos e a proposta de Internato em Psicologia; contribuições de um estágio no modelo de Internato e colaborações da professora junto aos alunos em campo.

\section{Resultados e discussão}

\section{Os estágios supervisionados básicos: a proposta de um Internato em Psicologia}

Os estágios supervisionados devem ser configurados em dois níveis: básico e específico (Resolução $n^{\circ} 5$, 2011). O estágio supervisionado básico abarca a integração das competências e habilidades e o desenvolvimento de práticas delimitadas no núcleo comum, que representa a perspectiva generalista da formação. $O$ âmbito do estágio específico consiste em aprofundar a ênfase assumida pelo projeto político pedagógico (PPP) do curso de Psicologia de cada instituição, sendo requisitado o desenvolvimento de práticas integradas das competências, habilidades e conhecimentos apropriados à referida ênfase do curso.

As DCN preconizam que, para a formação em Psicologia, as competências referem-se ao desenvolvimento no graduando de execuções e atuações psicológicas que visam a assegurar um domínio mínimo 
de conhecimentos nas diversas áreas da Psicologia e a aptidão para usá-los em âmbitos distintos que exigem a pesquisa, análise, avaliação, prevenção e atuação em processos psicológicos e psicossociais e na promoção da qualidade de vida. A carga horária integrada dos estágios básico e específico deve completar o mínimo de $15 \%$ da carga horária total do curso (Resolução n. 597, 2018).

Os estágios encontram-se no eixo estruturante dos componentes curriculares referentes às práticas profissionais, que visam garantir um núcleo básico de saberes e conhecimentos específicos. Reconhecemos que os estágios possibilitam a aproximação da prática profissional, de maneira mais concreta, menos idealizada e amplia as possibilidades de ação da psicóloga, uma vez que outras atividades, para além da psicoterapia, se tornam factíveis. Também viabilizam a compreensão da importância do trabalho em equipe e interinstitucional. No artigo $24^{\circ}$, o Conselho Nacional de Saúde (CNS) define os estágios obrigatórios supervisionados como atividades de formação, que tenham um grau crescente no que se refere à complexidade, busquem a interlocução de diferentes componentes curriculares, e que incluam as demandas regionais e territoriais, além da promoção de direitos humanos (Resolução n. 597, 2018). Ainda seguindo os parâmetros dessa regulamentação, os estágios também têm a proposta estimular criticamente a consolidação e a integração entre conhecimentos e práticas concernentes à formação da psicóloga, de modo a garantir a promoção de políticas públicas, a interdisciplinaridade e a interprofissionalidade (Resolução n. 597, 2018).

Nesse sentido, o Internato em Psicologia, implantado desde 2012, apresenta-se como uma experiência inovadora de ensino em serviço, presente em um curso de Psicologia de uma faculdade particular de Salvador, Bahia, cujas principais características são a oferta de cursos da área de saúde e a valorização da articulação teoria-prática (Daltro, Cajado, Oliveira, Silva \& Matos, 2013). Ele se localiza como um estágio básico supervisionado, obrigatório, por compor o currículo, e que privilegia a aprendizagem a partir das experiências em quatro campos de prática nas áreas de: Psicologia das Organizações e do Trabalho e nos âmbitos da Saúde, nos contextos da atenção básica, secundária e terciária, constituindo quatro rodízios.
Essas práticas supervisionadas são estruturadas em dez semanas, ocorrem no sétimo e no oitavo semestres, sendo mediadas por professoras com experiência nas referidas áreas de atuação, que oferecem assistência contínua e direta ao estudante em campo. Em termos de carga horária, possuem doze horas semanais de atividades teórico-práticas, em grupos pequenos entre seis e dez estudantes por período de prática, totalizando 120 horas para cada campo de atuação. Assim, em um semestre, o aluno cursa dois rodízios do Internato, ao longo de 20 semanas, totalizando 240 horas nessa modalidade de estágio básico. Geralmente, cada rodízio conta com a imersão de, no mínimo, oito horas semanais nos campos de práticas, e, ao final de todo o Internato (dois semestres), o estudante cumpre 480 horas relacionadas ao saber-fazer do psicólogo.

Por ser uma aproximação teórico-prática das atividades em psicologia, durante o quarto ano do curso, a experiência tem possibilitado que o estudante realize um processo de transição para um papel mais ativo na sua própria formação, ao experienciar a práxis da psicóloga nas áreas da Saúde e do Trabalho, as duas ênfases escolhidas pelo curso dessa faculdade.

Essa modalidade de aprendizado em serviço visa o desenvolvimento de competências conceituais, procedimentais e atitudinais nos estudantes. Apesar da dificuldade em distinguir com exatidão cada uma dessas competências, as conceituais estão relacionadas a conteúdos abordados ao longo do curso, como entrevista, avaliação, diagnóstico, psicoprofila$x i a$, tipos de atividades que podem ser desenvolvidas pela psicologia. As competências procedimentais dizem respeito à condição de realizar uma entrevista, identificar se há ou não demanda para acompanhamento psicológico, realizar avaliação de saúde mental em uma visita domiciliar, discutir uma situação com a equipe multidisciplinar etc. As atitudinais se referem à possibilidade de desenvolver relações em grupo de maneira construtiva, identificar limites na própria atuação, estabelecer uma relação responsável com todos os envolvidos na prática que exerce, entre outras características. Assim, essas atividades devem acontecer de modo a compreender o funcionamento dos campos de atuação, planejar intervenções adequadas às demandas do campo de prática, desenvolver habilidades interpessoais, aprofundar as possibilidades de intervenção em cada área de atuação e lidar com as questões éticas e relacionais emergentes nos campos da saúde e do trabalho. 
Uma vez descrita a estrutura básica do Internato em Psicologia, localizando-o em uma instituição, é possível trazermos algumas reflexões acerca das motivações para a sua estruturação tal como está atualmente. O modelo de estágio básico foi fundamentado pela teoria da aprendizagem sociointeracionista, uma vez, na estruturação do Internato, compartilhou-se da ideia de que a atividade humana ocorre através da mediação: o contato com pessoas mais experientes favorece a resolução de problemas percebidos, inicialmente, como difíceis ou impossíveis de serem enfrentados individualmente (Lima, 2017).

A zona de desenvolvimento proximal (Vigotski,1984/2007), descrita na teoria de aprendizagem sociointeracionista, é percebida no cotidiano do processo de aprendizagem, quando a professora e o grupo de alunos estudam os conteúdos a serem aprendidos, revisam conteúdos já abordados nos semestres anteriores, e identificam possibilidades de soluções ou compreensões dos problemas identificados nos campos de atuação da psicóloga. A interação social, intrínseca ao processo de ensino-aprendizagem, mediada pela professora, consiste num espaço democratizado, de troca e compartilhamento do conhecimento teórico, do saber-fazer da atuação da Psicologia e das atitudes pessoais e profissionais necessárias àquele campo de prática.

A partir da mediação, o sujeito implica-se na interação com o mundo através da consciência e constrói sentidos e significados para a experiência vivida. Nesse sentido, a professora agrega ao modelo por trazer suas habilidades e competências como experiência prática, auxilia o estudante a passar de um nível inicial de aprendizagem, muito voltado para a aquisição de conhecimento, para explorar suas possibilidades de aprendizagem de intervenção técnica pela interação com o usuário do serviço, com os funcionários da empresa, bem como com o grupo de estudantes e a própria professora (Daltro \& Pondé, 2017).

Assim, o Internato em Psicologia está organizado de uma maneira que viabiliza a inserção do estudante em espaços de práticas consoantes com as ênfases do curso, proporcionando a todos experiências múltiplas, antes da escolha do estágio específico, ao tempo em que, pela presença da professora junto aos alunos nos campos, potencializa o aprendizado, construindo leituras variadas das atividades a serem desempenhadas pela psicóloga.

\section{Presença da professora no campo de estágio: reflexões acerca do aprender-fazer juntos}

Identificamos que o Internato em Psicologia, tal como está estruturado, com base no processo de ensino-aprendizagem sociointeracionista, de maneira rotativa e com grande carga horária, incentiva o aluno a interagir com problemáticas emergentes do campo de prática, ao pensar numa práxis, discutindo com os colegas, professores, trabalhadores da saúde e percebendo suas próprias emoções, que entram nesse contexto formativo como fundamentais para o autorreconhecimento e para a construção de uma identidade profissional.

A presença da professora no campo de prática, realizando, se necessário, as mesmas atividades que são propostas aos estudantes, e a possibilidade de ter um discente observando o seu fazer, tem sido reconhecido por nós como um aspecto que agrega conhecimentos para a formação do estudante. Ao refletirmos, enquanto professoras, acerca da nossa própria prática na formação em Psicologia, nos deparamos com a quase total ausência de experiências em que tenhamos acompanhado um professor, ou até mesmo um psicólogo do campo de estágio específico, em atendimento ou atuando nas instituições em que passamos enquanto estudantes. Lembramo-nos de um ensino de Psicologia muito teórico, em que a prática era organizada mais no campo da idealização do que com elementos realmente vividos.

A discussão sobre formas de fazer, entrelaçamentos entre teorias e intervenções, sentimentos vividos e dificuldades percebidas eram praticamente ausentes. A proposta do Internato é diminuir a distância entre essa construção imaginada do fazer da psicóloga e a real tessitura da sua atividade no cotidiano, através da atuação de uma professora que pode tanto ser observada, como observar o estudante em sua atuação.

Assim, a presença da professora é compreendida por nós como uma via não apenas de apresentação da atividade, mas também de discussão de formas de exercer o papel de psicóloga, por meio do manejo de situações que acontecem in loco, de reflexão sobre impasses vividos, de tomada de decisões éticas e articuladas com o campo de práticas. Ou seja, a presença da professora pode ser problematizada como uma forma de catalização da compreensão do saber-fazer da psicóloga engajada em contextos. 
Para tanto, reconhecemos um elemento fundamental nesse processo de aprendizagem que é o de se colocar como agente ativo na construção das próprias habilidades e conhecimentos teóricos. Identificamos que, o grande período em que professoras e alunos permanecem juntos no campo de prática, ao menos oito horas semanais, é um elemento dinamizador da vinculação: entre professora e aluno, entre grupo de estudantes e entre o grupo da faculdade e os profissionais do campo em que estão inseridos. A vinculação é um fator que, como defende Pichon-Rivière (1998), favorece que o outro se torne significativo para nós e, a partir desse processo vinculativo, é possível trabalhar com elementos de pertencimento. Assim, as pessoas do nosso grupo e, em seguida, o campo de prática em que estamos, passa a ser significativo para nós, de tal forma que a nossa atuação deixa de ser alienada e se torna comprometida e crítica, com objetivos de garantir ou tentar desenvolver, formas para que todos os que estão envolvidos sintam-se valorizados pelo que fazem e pelo que são.

Nesse sentido, os estudantes começam a se sensibilizar com o mundo do outro, identificando aspectos de uma realidade que lhe é estranha, mas que passa a compor o seu mundo, como a preocupação em relação ao fato de que alguns usuários do serviço e seus acompanhantes não sabem usar o elevador da instituição, por terem o hábito de frequentarem casas e não edifícios. Essas pessoas são, em sua maioria, oriundas de cidades do interior da Bahia e, mais especificamente, da zona rural, tendo uma forma de lidar com o território - espaço de mediação entre mundo e sociedade - diferente da dos alunos, em sua maioria. Com esse exemplo, podemos perceber como fica mais fácil para esse estudante visualizar o que pode ser morar em outra cidade, que não seja a capital do Estado, assim como imaginar: que existem outras formas de lidar com o espaço-tempo, que tantos outros recursos podem não estar disponíveis a essa pessoa e que o trabalho em saúde é mais amplo do que o diagnóstico e o tratamento, por exemplo.

Nessa perspectiva, o desenvolvimento da empatia para compreender a realidade do usuário do serviço foi explicitado por Ramírez (2016) como um dilema no processo de aprendizagem dos estudantes de Psicologia frente aos estágios e, para enfrenta-lo o autor propõe que as vivências sejam compartilhadas com o usuário, de modo a reduzir a distância entre o mundo do graduando e o mundo da pessoa atendida por ele, a partir do vislumbre de realidades diferentes e concretas.

Com a inserção do aluno nos cenários de práticas, de maneira gradual e antes dos estágios específicos, é possível auxiliá-lo na compreensão de uma população que, em termos de saúde, apresentará como queixas: o nervosismo, a insônia, a irritabilidade, a vontade de não ir trabalhar, e entrever que esses sujeitos podem ser pertencentes a um grupo que possui o que Sawaia (2014) problematizou como sofrimento ético-político, que diz respeito aos engendramentos relacionados à exclusão, à opressão e ao desvalor.

É difícil para uma pessoa habitualmente questionar certos procedimentos adotados pela equipe, mas isso se complexifica na medida em que outros elementos compõem esse cenário, como estar longe de casa, doente, necessitando de cuidados diretos da equipe de saúde e sem o domínio do local físico em que está instalada. Assim, ao poder ver essas tantas pessoas com realidades de vida diversas, pessoas atendidas por essas futuras psicólogas não entrarão rapidamente em categorias nosológicas típicas da racionalidade biomédica, ficando menos reféns dessa perspectiva, ao se depararem com uma abordagem psicológica compreensiva e que contempla o que os contextos podem produzir em termos de saúde, doença e cuidado. Podemos afirmar, por exemplo, que conviver com essas realidades dos campos de práticas, juntamente com o treino em evoluções psicológicas, registro em prontuário e preparação de relatórios psicológicos contribuem para ações mais cuidadosas e melhores interações com outros profissionais.

Ao mesmo tempo em que temos um estudante que vai ampliando as suas noções de realidade, modos de vida, significados do adoecimento e do cuidado, percebemos que estar em um campo de prática, acompanhado todo tempo pela presença da professora, contribui para experiência de desenvolvimento da autonomia do estudante, aqui compreendida como uma autonomia mediada. Essa mediação tem o propósito de retomar diversos conteúdos já abordados teoricamente, valorizar o que foi apreendido, dar direcionamento às atividades que serão desenvolvidas, destacar quais as habilidades serão necessárias para o desenvolvimento de determinadas intervenções, validar experiências vividas, construir um espaço-tempo de trocas e acolhimentos das experiências difíceis e prazerosas. 
Durante todo o período do Internato, são comuns preocupações dos alunos que fazem referência a como essas práticas de imersão com a professora auxiliam-nos a se aproximarem com mais clareza do papel do psicólogo, a articularem o que aprenderam "teoricamente" com o fazer do momento, assim como relatos que abordam a dificuldade e complexidade do trabalho do psicólogo, a sensação de cansaço após a prática e a percepção de que achavam que não conseguiriam desempenhar uma atividade. Também são comuns dúvidas sobre como "proceder" caso alguém chore, quais perguntas são pertinentes em uma primeira entrevista com um paciente hospitalizado, o que é típico de um acolhimento e o que é mais característico de psicoterapia. Nesse sentido, trazemos à reflexão o quanto é importante estar junto a esses estudantes ao longo dessas atividades, construindo um campo de sensibilidades, viabilizando a expressão de dúvidas, sentimentos e sensações que, quando conhecidas, podem ser abordadas, colaborando para um período de estágio obrigatório mais maduro e baseado em escolhas mais conhecidas e sustentáveis.

Ainda que a discente tenha experienciado práticas ao longo do curso, identificamos que essa proposta de Internato em Psicologia contribui com essa transição entre ser estudante e ser psicóloga, muito por colaboração dessa autonomia mediada ao lidar com os contextos. Outro aspecto frequentemente identificado refere-se à dúvida sobre a sua capacidade para atender pessoas, que emerge, por vezes, em forma de insegurança, ansiedade e medo em desenvolver a atividade. Ao retomar os conhecimentos teóricos, articulando-os com o campo de prática, o grupo de estudantes vai se dando conta de que vivenciaram três anos da formação em Psicologia e que possuem recursos técnicos, pessoais e profissionais para lidar com o desconhecido, que essa prática inicialmente representa.

Ao longo desses quatro anos em questão, identificamos que o primeiro dia de prática costuma ser permeado por muitas perguntas, silêncios ou olhares que solicitam apoio. Essas reações emocionais foram identificadas em relação à primeira entrevista clínica, à primeira visita domiciliar no território da UBS, ao primeiro grupo em sala de espera que realizam, em que citam os sentimentos de ansiedade, angústia, despreparo, incapacidade e curiosidade como possibilidades de vivência emocional diante das experiências de estágio, pois há uma pressuposição de muitos estudantes de que os anos de formação em sala de aula podem não os ter preparado para a prática (Ribeiro, Tachibana \& Aiello-Vaisberg, 2008). Consideramos que o exercício de lidar com a ambiguidade da vivência frente ao desconhecido representa um dos aprendizados que a Psicologia proporciona enquanto campo de conhecimento múltiplo e diverso.

Alguns dos dilemas e tensões vivenciados identificados pelas professoras do Internato também são discutidos por Ramírez (2016), quanto à vivência dos estágios, que representam a transição da posição de estudante para a prática profissional. Um dilema refere-se à passagem das aulas teóricas para a prática da profissão, sendo este um ponto de tensão nesta transição. Outro configura-se como um questionamento sobre o atendimento das particularidades do caso, sendo necessário para o estudante exercitar a escuta e deixar em suspenso suas questões, ideias e expectativas. Esse desafio de lidar com as distintas emoções evocadas na atuação da profissional de Psicologia, pode ser amenizado a partir da supervisão, que acolhe o que foi possível para o estudante em sua experiência inicial com o campo de atuação e apresenta indicações teóricas, sugestões para o desenvolvimento de habilidades práticas e competências que possam favorecer uma aproximação do estudante com a realidade do usuário do SUS.

Um aspecto dilemático costumeiramente vivenciado pelos estudantes de Psicologia em nossa experiência docente e que foi discutido por Ramírez (2016), trata-se da regulação emocional do estudante, a necessidade de transmitir segurança e compromisso com sua prática. O ponto de tensão existente, que, gradativamente, os estudantes aprendem com a experiência para se regularem emocionalmente, configura-se no aproveitamento dos recursos de mediação, como o espaço da supervisão.

Reconhecemos também que o grupo de estudantes tem uma função importante nesse acolhimento das emoções entre os colegas, pois, ao se sentirem confortáveis para partilhar suas questões técnicas, teóricas e práticas no grupo, todos se enxergam como atores do processo de aprendizagem e esse reconhecimento do caminho processual do desenvolvimento de competências da aprendizagem favorece que o grupo identifique afinidades e potências entre os participantes dessa interação. Cabe à professora estar atenta ao funcionamento de cada grupo de 
estudantes, que é único, complexo e requer observação para identificar os aspectos não-verbais da comunicação e o que pode ser expresso nos grupos para construir o aprendizado coletivo. Cada configuração grupal solicita um modo de funcionar da professora, que ocupa a função de supervisora e mediadora do processo de aprendizagem. A heterogeneidade do grupo costuma possibilitar o aprendizado de competências conceituais, procedimentais e atitudinais, ampliando a perspectiva para incluir a alteridade. A supervisão tende a ser um espaço de acolhimento emocional e de trocas teórico-práticas.

Os pequenos grupos permitem que os estudantes compartilhem seus questionamentos, dificuldades, aprendizados e recursos para o enfrentamento das situações. Nossa experiência docente coaduna com o que foi discutido por Fuentes-Rojas (2011), que destaca que as trocas das experiências práticas emergem a partir das teorias que os estudantes têm se apropriado e dos fundamentos e estratégias que as professoras também agregam às discussões, como contribuições para o aprimoramento do grupo em supervisão.

No nosso cotidiano, percebemos que os grupos apresentam necessidades de acolhimento, graus de resistência com o ambiente de prática e comprometimento com a tarefa de aprender e compartilhar nos mais distintos níveis de implicação. O sentido construído pelo estudante para a atuação psicológica, o grau de motivação e realização do curso de Psicologia interferem nessa implicação com as atividades teórico-práticas.

No espaço da supervisão, é de praxe que sejam ressaltadas a importância do estudo, da psicoterapia pessoal e da supervisão para a formação em Psicologia, pois a professora precisa manejar e encaminhar as demandas que extrapolam o contexto educacional. O suporte psicológico, psicopedagógico e de outros profissionais da saúde pode ser sugerido ao aluno, sempre que houver possibilidade para tal e for percebido como um aspecto que pode agregar na sua experiência, como uma possibilidade de auxílio ao estudante frente a alguma dificuldade que ele apresente e que tenha reverberação, seja nas suas intervenções com os usuários de saúde, seja na percepção de aprendizado.

Consideramos que esse aspecto sempre precisa ser abordado com muito cuidado e respeito ao discente, sem confundir os papeis de professora e psicóloga, mas temos percebido, ao longo desses anos com esse modelo de estágio básico, que a relação que se estabelece com o estudante ao longo do Internato tem permitido que esses encaminhamentos sejam sentidos como uma ação de cuidado e atenção da professora, no que se refere à saúde e ao desenvolvimento de competências.

A modalidade do Internato em Psicologia foi pensada com a supervisão direta das professoras em campo e essa concepção é um dos trunfos desse modelo de estágio, tendo em vista que os estudantes se sentem mais amparados frente ao início das práticas, tendo uma professora "ao lado" para discutir situações mais complexas, supervisionar e acompanhar o atendimento do estudante, observando sua atuação e intervindo, caso seja necessário.

Percebemos que a interação com os estudantes favorece o desenvolvimento de habilidades nas professoras, pois com a construção da interação com tantos estudantes, identificamos a potência que os grupos possuem em sua heterogeneidade de vivências e diversidades. A atividade docente é desafiadora, pela multiplicidade de conhecimentos compartilhados no cotidiano da sala de aula e pelas experiências práticas que a Psicologia nos proporciona, por ensinar e aprender através dos olhares de cada estudante e de cada pessoa atendida. A complexidade da docência da Psicologia impulsiona-nos a buscar conhecimento para aprimorar o nosso fazer, estabelecer interlocuções com outros saberes e produções científicas, além de requerer uma competência atitudinal para a construção de relações e interações com estudantes e profissionais da Psicologia dos campos de prática, assim como das equipes em que estamos inseridas.

No entanto, algumas críticas a essa proposta de ensino também estão presentes. Algumas vezes esse componente curricular, por possuir extensa carga horária e dias variados de práticas, é compreendido como um dificultador para a participação de alunos em estágios extracurriculares, o que também impacta na sua formação e no contato com áreas de atuação que não estão em destaque pela faculdade. Outro aspecto que também tem sido fruto de discussões entre o grupo de professoras que compõe o Internato é o cansaço proveniente de tantas horas dedicadas ao componente curricular e advindo da tensão presente em estar com um grupo de alunos e se relacionar com as demandas do campo em que estão inseridos. 
Estar nesse lugar de mediador, seja mais voltado a aspectos teóricos e formas de fazer, seja com ênfase na intensidade dos conflitos presentes nas instituições ou campos de práticas e que reverberam no grupo de alunos, gera também tensões vividas por essas professoras, que, ao ocuparem esse lugar híbrido (psicóloga e professora) sentem em si as dificuldades em desempenharem esse papel complexo. É vivido em cada professora do campo de atenção terciária, por exemplo, a tensão entre o que foi discutido com os estudantes e como a equipe costuma resolver seus conflitos com os pacientes. É possível compreender o acontecido e discutir maneiras para tentar mudar a situação e, ao mesmo tempo, respeitar os atores que estavam envolvidos na cena conflituosa, No entanto, esse manejo envolve percepção dos próprios sentimentos, espaço para o diálogo, além do reconhecimento da multiplicidade de respostas, frente a uma mesma situação. Reconhecermo-nos como profissionais que também se sentem inseguras e que nem todas as propostas são aceitas é um exercício longo, que requer uma importante revisão das próprias características. Identificamos que existem muitos avanços para a formação do estudante com essa prática de Internato em Psicologia, mas ela exige, dos envolvidos, muita reflexão e estudo. A proposta do Internato requer que sempre retomemos seus objetivos pedagógicos, que envolvem a aproximação dos campos de prática de maneira mais cuidadosa e aprofundada.

Concernente com o PPP do curso de Psicologia da Instituição, identificamos que o Internato em Psicologia possibilita a interação contínua entre a teoria e a prática, construindo progressivamente, com o estudante, o sentido da aprendizagem pela experiência com os campos de atuação. Compreendemos que esse modelo de estágio básico rotatório favorece o processo de construção da identidade profissional e amadurecimento pessoal do estudante, mediado pela experiência nos distintos contextos de práticas com os grupos, professoras, usuários do serviço e outros profissionais das equipes de saúde.

\section{Considerações finais}

O histórico da formação em Psicologia e a importância dos estágios supervisionados foram ressaltados através do relato de experiência das professoras do Internato em Psicologia. Esse modelo de estágio básico, que ocorre através da mediação da professora com os campos de práticas e os pequenos grupos de estudantes, visa o desenvolvimento de competências de modo a construir uma atuação contextualizada, crítica e proponente de mudanças na área da saúde, aqui em destaque. Algumas são as especificidades dessa prática de estágio com suporte direto das professoras, tendo a supervisão e a integração grupal entre os estudantes e o campo de prática como elementos fundamentais para a construção de um fazer psicológico ético e socialmente implicado, mas que também apresenta limites no seu alcance, como já ponderado.

Salientamos que a possibilidade de experienciar quatro campos de prática distintos favorece a ampliação do repertório do estudante para analisar a realidade da população assistida e permite que os estudantes interajam com muitos colegas, usuários, membros das equipes e, com isso, possam identificar seus recursos e desafios para a atuação futura na Psicologia.

Como professoras do Internato, acompanhamos reações de ansiedade de estudantes no início do estágio, o medo de errar, de ser invasivo e de causar algum prejuízo à saúde das pessoas que estão sendo atendidas por eles. Identificamos que é esperado que os estudantes se sintam pouco preparados ao se depararem com o início da prática da Psicologia e, também a partir dessa percepção de insegurança, eles possam refletir acerca da importância em se prestar uma assistência ética e socialmente comprometida.

Acolher as incertezas ao se defrontar com o novo, com o aprendizado, com as resistências individuais e coletivas, bem como com as situações vivenciadas pela população assistida nos contextos da saúde brasileira consistem em alguns dos aspectos tratados no presente artigo. A supervisão consolida-se como um lócus de cuidado dos atores envolvidos no estágio pelas trocas em relação aos conhecimentos técnicos, às questões emocionais e relacionais e ao desenvolvimento da autonomia dos estudantes, mediada pela experiência da prática docente.

Nesse sentido, acreditamos que identificar as contribuições dessas interações nos campos de prática nos auxilia a propor novas formas de fazer Psicologia. 
O SUS, ao ampliar a prática de atenção à saúde, nos insere em uma realidade em que precisamos nos responsabilizar pela expansão da nossa práxis nesses espaços de cuidado. Novos estudos, com as mais diversas metodologias, podem auxiliar na compreensão desse momento que vivemos, após a implantação das DCN.

\section{Contribuições das autoras}

Ambas as autoras conceberam, redigiram e aprovaram o artigo.

\section{Conflitos de interesses}

Nenhum conflito financeiro, legal ou político envolvendo terceiros (governo, empresas e fundações privadas, etc.) foi declarado para nenhum aspecto do trabalho submetido (incluindo, mas não se limitando a subvenções e financiamentos, participação em conselho consultivo, desenho de estudo, preparação de manuscrito, análise estatística, etc.).

\section{Referências}

Antunes, M. A. M. (2006). A consolidação da psicologia no Brasil (1930-1962): sistematização de dados e algumas aproximações analíticas. Psicologia da Educação, (22), 79-94. http://pepsic.bvsalud.org/scielo.php?script=sci_ arttext\&pid=S1414-69752006000100005\&lng=pt\&tlng=pt

Antunes, M. A. M. (2012). A Psicologia no Brasil: um ensaio sobre suas contradições. Psicologia: Ciência e Profissão, 32(spe), 44-65. https://doi.org/10.1590/S1414-98932012000500005

Bernardes, J. S. (2012). A formação em psicologia após 50 anos do primeiro currículo nacional da psicologia - alguns desafios atuais. Psicologia: Ciência e Profissão, 32(spe), 216-231. https://doi.org/10.1590/S1414-98932012000500016

Collares-da-Rocha, J. C. C., \& Lima, R. S. (2019). Formação e regulamentação em psicologia na Arquivos Brasileiros de Psicotécnica. Arquivos Brasileiros de Psicologia, 71(3), 12-22. http://dx.doi.org/10.36482/1809-5267. ARBP2019v71i3p.12-22

Correia, A. M. B., \& Dantas, C. N. C. B. (2017). O fazer psicológico na ditadura civil militar. Psicologia: Ciência e Profissão, 37(spe), 71-81. https://doi.org/10.1590/1982$\underline{3703050002017}$
Daltro, M. R., \& Pondé, M. P. (2017). Internato em psicologia: aprender-a-refletir-fazendo em contextos de prática do SUS. Revista Psicopedagogia. 34(104), 169-79. http://pepsic. bvsalud.org/scielo.php?script=sci_arttext\&pid=\$0103$84862017000200007 \&$ Ing=pt\&t|ng=pt

Daltro, M., Cajado, M. C.V., Oliveira, M. L. A., Silva, S. M. B., \& Matos, N. M. M. (2013). Internato em Psicologia: uma prática interdisciplinar assistida. In C. A. F. Danon \& M. R. Daltro (Orgs), Psicologia profissão de saúde: da formação à prática profissional (pp.48-66). Escola Bahiana de Medicina e Saúde Pública.

Dimenstein, M. D. B. (1998). O psicólogo nas Unidades Básicas de Saúde: desafios para a formação e atuação profissionais. Estudos de Psicologia (Natal), 3(1), 53-81. https://doi. org/10.1590/S1413-294X1998000100004

Dimenstein, M., \& Macedo, J. P. (2012). Formação em Psicologia: requisitos para atuação na atenção primária e psicossocial. Psicologia: Ciência e Profissão, 32(spe), 232245. https://doi.org/10.1590/S1414-98932012000500017

Esch, C. F., \& Jacó-Vilela, A. M. (2012). A regulamentação da profissão de psicólogo e os currículos de formação psi. In A. M. Jacó-Vilela, A. C. Cerezzo, \& H. B. C. Rodrigues (Orgs.), Clio-Psyché Hoje: fazeres e dizeres psi na história do Brasil (pp.3-12). https://doi.org/10.7476/9788579820618

Fernandes, M. I. A. (2001). Abandono das instituições: construção de políticas públicas e universidade. Psicologia USP, 12(2), 11-27. https://doi.org/10.1590/S0103-65642001000200002

Ferreira Neto, J. L. (2008). Práticas transversalizadas da clínica em saúde mental. Psicologia: Reflexão e Crítica, 21(1), 110-118. https://doi.org/10.1590/S0102-79722008000100014

Fuentes-Rojas, M. (2011). Psicologia e saúde: a terapia comunitária como instrumento de sensibilização para o trabalho com comunidades na formação do Psicólogo. Psicologia: Ciência e Profissão, 31(2), 420-439. https://doi. org/10.1590/S1414-98932011000200016

Hüning, S. M., Costa, L. D. A. A., Silva, A. K., \& Silva, S. J. P. (2013). Estágios e Extensões na Formação do Psicólogo para o Trabalho no Sistema Único de Saúde. Psico, 44(3), 319330. http://revistaseletronicas.pucrs.br/ojs/index.php/ revistapsico/article/view/15805

Jacó-Vilela, A. M., \& Degani-Carneiro, F. (2012). Da clínica privada às instituições: uma trajetória do psicólogo em suas relações com a saúde. In M. M. Rezende, \& M. G. V. Heleno (Orgs.), Psicologia e promoção de saúde em cenários contemporâneos (pp.17-40). Vetor. 
Lei n. 4.119, de 27 de agosto de 1962. Dispõe sobre os cursos de formação em psicologia e regulamenta a profissão de psicólogo. https://www2.camara.leg.br/legin/fed/lei/19601969/lei-4119-27-agosto-1962-353841-publicacaooriginal1-pl.html

Lei n. 9.394, de 20 de dezembro de 1995. Estabelece as diretrizes e bases para a educação nacional. http://portal.mec.gov.br/ setec/arquivos/pdf/LF9394_96.pdf

Lima, V. V. (2017). Espiral construtivista: uma metodologia ativa de ensino-aprendizagem. Interface - Comunicação, Saúde, Educação, 21(61), 421-434. https://doi.org/10.1590/1807$\underline{57622016.0316}$

Lisboa, F. S., \& Barbosa, A. J. G. (2009). Formação em Psicologia no Brasil: um perfil dos cursos de graduação. Psicologia: Ciência e Profissão, 29(4), 718-737. https://doi.org/10.1590/ S1414-98932009000400006

Lüchmann, L. H. H., \& Rodrigues, J. (2007). O movimento antimanicomial no Brasil. Ciência \& Saúde Coletiva, 12(2), 399-407. https://doi.org/10.1590/S1413$\underline{81232007000200016}$

Macedo, J. P., \& Dimenstein, M. (2011). Expansão e interiorização da Psicologia: reorganização dos saberes e poderes na atualidade. Psicologia: Ciência e Profissão, 31(2), 296-313. https://doi.org/10.1590/S1414-98932011000200008

Macedo, J. P., \& Dimenstein, M. (2016). Efeitos do saber-fazer de psicólogos na Saúde Mental do Piauí. Fractal: Revista de Psicologia, 28(1), 37-45. https://doi.org/10.1590/1984$\underline{0292 / 1034}$

Mello, R. A., \& Teo, C. R. P. A. (2019). Psicologia: entre a atuação e a formação para o sistema único de saúde. Psicologia: Ciência e Profissão, 39(e186511), 1-16. https://doi. org/10.1590/1982-3703003186511

Mendes, F. M. S., Fonseca, K. A., Brasil, J. A., \& Dalbello-Araújo, M. (2012). Ver-Sus: relato de vivências na formação de Psicologia. Psicologia: Ciência e Profissão, 32(1), 174-187. https://doi.org/10.1590/S1414-98932012000100013

Pichon-Rivière, E. (1998). Teoria do vínculo. Martins Fontes.

Pitombeira, D. F., Xavier, A. S., Barroso, R. E. C., \& Oliveira, P. R. S. (2016). Psicologia e a Formação para a Saúde: Experiências Formativas e Transformações Curriculares em Debate. Psicologia: Ciência e Profissão, 36(2), 280-291. https://doi. org/10.1590/1982-3703001722014

Ramírez, L. (2016). Dilemas y tensiones en la transición del aula universitaria a la práctica preprofesional en estudiantes de psicología. Educación, 25(48), 29-51. https://doi. org/10.18800/educacion.201601.002
Resolução $n$. 5, de 15 de março de 2011. Institui as Diretrizes Curriculares para os cursos de Psicologia, estabelecendo normas para o projeto pedagógico complementar para a Formação de Professores de Psicologia. http://portal.mec.gov.br/index.php?option=com docman\&view=download\&alias=7692-rces005-11 pdf\&ltemid $=30192$

Resolução $n$. 597, de 13 de setembro de 2018. Recomendações do Conselho Nacional de Saúde à proposta de Diretrizes Curriculares Nacionais do curso de graduação Bacharelado em Psicologia. www.in.gov.br/materia/-/ asset_publisher/Kujrw0TZC2Mb/content/id/52748594/ do1-2018-11

Ribeiro, D. P. S. A., Tachibana, M., \& Aiello-Vaisberg, T. M. J. (2008). A experiência emocional do estudante de Psicologia frente à primeira entrevista clínica. Aletheia, (28), 135145. http://pepsic.bvsalud.org/scielo.php?script=sci_ arttext\&pid=S1413-03942008000200011\&lng=pt\&nrm=is o\&tlng=pt

Romano, B. W. (1999). A prática da psicologia clínica em hospitais. Casa do Psicólogo.

Rosato, C.M. (2011). Psicologia e Direitos Humanos: cursos e percursos comuns. Psicol. rev, 20(1), 11-27. https:// pesquisa.bvsalud.org/portal/resource/pt/lil-707498

Sawaia, B. (2014). As artimanhas da exclusão: análise psicossocial e ética da desigualdade social. Vozes.

Silva Neto, W. M. F., \& Oliveira, W. A. (2015). Práticas do Supervisor Acadêmico na Formação do Psicólogo: Estudo Bibliométrico. Psicologia: Ciência e Profissão, 35(4), 10421058. https://dx.doi.org/10.1590/1982-3703001632014

Silva, N. O., Pinheiro, M. A., \& Laurendon, C. E. (2020). Construção de significados e ambiguidades na supervisão de estágio em psicologia. Psicologia USP, 31, e200064. https://doi. org/10.1590/0103-6564e200064

Soares, L. L. M., \& Veríssimo, L. J. (2010). A formação do aluno na graduação em Psicologia pela Pedagogia de Paulo Freire. Psicologia: Ciência e Profissão, 30(3), 588-603. https://doi. org/10.1590/S1414-98932010000300011

Vigotski, L. S. (1984/2007). A formação social da mente. (7a ed.). Martins Fontes.

Yamamoto, O. H. (2000). A LDB e a Psicologia. Psicologia: Ciência e Profissão, 20(4), 30-37. https://doi.org/10.1590/S1414$\underline{98932000000400004}$ 